\title{
Pengaruh bahan pengisi serat kaca terhadap sifat fisik dan kristalinitas polipaduan PCIABS
}

\author{
The effect of glass fiber on the physical and crystallinity \\ properties of PC/ABS polyblend
}

\author{
Dwi Wahini Nurhajati*, Muhammad Sholeh, Ihda Novia Indrajati, Ike Setyorini \\ Balai Besar Kulit, Karet, dan Plastik, Jl. Sokonandi No.9, Yogyakarta 55166, Indonesia \\ *Penulis korespondensi. Telp.: +62 274 512929, 563939; Fax: +62 274563655 \\ E-mail: dwiwahini@yahoo.com
}

Diterima: 7 April 2017 Direvisi: 10 Mei 2017 Disetujui: 12 Mei 2017

\begin{abstract}
This research aimed to determine the effects of the addition of glass fibers on the physical and crystallinity properties of $P C / A B S$ polyblends. The ratio of $P C / A B S$ used in this research was $75 / 25$, while the addition of glass fibers ranged from 0; 5; 10; to $15 \mathrm{phr}$ (based on the weight of PC/ABS). Polyblends of PC/ABS/glass fibers were prepared in a twin screw extruder. The test results showed that density and tensile strength of PC/ABS polyblends increased with an increase in the glass fiber content. The presence of glass fibers decreased MFI and impact strength of these PC/ABS polyblends. The functional groups were determined by the fourier transform infrared (FTIR) spectrophotometer while crystallinity was examined using X-ray diffractometer (XRD).
\end{abstract}

Keywords: PC/ABS polyblend, glass fiber, physical properties, crystallinity.

\section{ABSTRAK}

Tujuan penelitian ini untuk mempelajari pengaruh penambahan serat kaca terhadap sifat fisik dan kristalinitas polipaduan PC/ABS. Perbandingan PC/ABS yang digunakan pada penelitian ini adalah 75/25 dan serat kaca yang ditambahkan divariasi dari 0; 5; 10 dan 15 phr (berbasis pada berat PC/ABS). Polipaduan PC/ABS/serat kaca dibuat di dalam twin screw extruder. Hasil uji menunjukkan bahwa semakin banyak serat kaca, yang ditambahkan, menaikkan densitas dan kekuatan tarik polipaduan PC/ABS. Adanya serat kaca menurunkan MFI dan kekuatan impak dari polipaduan PC/ABS. Karakterisasi gugus fungsi ditentukan dengan spektrofotometer fourier transform infra red (FTIR) dan uji kristalinitas dengan $X$-ray diffractometer (XRD).

Kata kunci: polipaduan PC/ABS, serat kaca, sifat fisis, kristalinitas.

\section{PENDAHULUAN}

Polipaduan polikarbonat/akrilonitril butadiena stirena (PC/ABS) merupakan engineering thermoplastics yang penting dan banyak digunakan di industri otomotif maupun elektronika. PC/ABS menggabungkan sifat yang sangat baik dari dua bahan, ABS bersifat mudah dibentuk dan bahan PC mempunyai sifat mekanik, ketahanan impak, ketahanan panas, dan ketahanan terhadap sinar ultraviolet (UV) yang baik (Ho et al., 2015).

Penggunaan bahan pengisi (filler) di industri plastik saat ini sudah merupakan kebutuhan karena selain dapat mengurangi biaya, bahan pengisi juga dapat berperan secara fungsional seperti memodifikasi sifat mekanik dari plastik. Banyak jenis bahan pengisi yang dapat digunakan untuk membuat komposit dan memodifikasi sifat plastik, salah satunya adalah serat kaca (glass fiber). Serat kaca merupakan bahan penguat yang paling banyak digunakan dalam komposit berbasis termoplastik, karena bahan tersebut memiliki keseimbangan yang baik antara sifat yang dihasilkan dan biaya yang rendah (Hemanth et al., 2014). Namun, sifat akhir komposit ditentukan oleh kekuatan dan stabilitas dari interfase polimer dan serat. Serat gelas yang digunakan pada penelitian ini adalah 
tipe E-glass, menurut Avdeeva et al. (2016) serat kaca tipe E-glass komposisi terbesarnya adalah senyawa $\mathrm{SiO}_{2}$ sebesar $53 \%$.

Penelitian penggunaan fiberglass untuk memperkuat kompon PC dilakukan oleh Malinoski (2011), dimana dilaporkan bahwa penambahan fiberglass 5-50\% menaikkan kekakuan dan memperbaiki sifat mekanik tertentu. Demikian juga yang dilaporkan oleh Krishna et al. (2013) bahwa penambahan fiberglass $5-30 \%$ pada PC menaikkan kekuatan impak campuran PC/ABS 50/50. Samakrut et al. (2008) telah melakukan penelitian penambahan serat kaca pada polipaduan $\mathrm{PC} / \mathrm{ABS}$ ditinjau dari sifat reologi, suhu transisi gelas, suhu degradasi komposit dan juga morfologi. Gaji and Satyanarayana (2016) mempelajari karakterisasi dan sifat mekanik komposit ABS/serat kaca. Dari hasil penelitian tersebut belum ada yang membahas pengaruh serat kaca terhadap sifat mekanik, FTIR, dan XRD polipaduan PC/ABS.

\section{BAHAN DAN METODE Bahan Penelitian}

Bahan yang digunakan dalam penelitian ini adalah bahan komersial seperti akrilonitril butadiena stirena (ABS) injection grade Toyolac 700 314 , resin polikarbonat (PC) Wonderlite PC-110 injection grade, fiber glass chop strand ECS 13.3. Bahan aditif lain yang digunakan adalah aditif komersial yang banyak dijumpai di pasaran, seperti anti oksidan Irganox 1010 dan Irgafos P168, dan ABS-g-MA sebagai compatibilizer.

\section{Peralatan Penelitian}

Peralatan yang digunakan dalam penelitian ini meliputi alat proses dan alat uji meliputi twin screw extruder, tensile strength tester merek Troning Albert tipe QC II-M-18, hardness tester merek Toyoseiki (Durometer D), electron densimeter EW-200SG merek Mirage, alat uji melt flow index merek Tinius Olse-MP 1200, alat uji kuat impak Izod merek Toyoseiki, spektrofotometer fourier transform infra red (FTIR) merek Shimadzu Prestige-21, X-ray diffractometer (XRD) merek Shimadzu, scanning electron microscope (SEM) merek SEC-SNE 3200M.

\section{Metode Penelitian \\ Proses pencampuran}

Bahan plastik $\mathrm{PC}$ dan ABS, sebelum dicampur, dilakukan pemanasan awal selama 4 jam berturutturut pada suhu $100^{\circ} \mathrm{C}$ dan $80^{\circ} \mathrm{C}$. Selanjutnya ba- han dicampur di dalam twin screw extruder sesuai formula yang ditetapkan pada suhu $230^{\circ} \mathrm{C}-260^{\circ} \mathrm{C}$. Perbandingan $\mathrm{PC} / \mathrm{ABS}$ yang digunakan pada penelitian ini adalah $75 / 25$. Dasar pengambilan perbandingan ini karena, menurut penelitian Krishna et al. (2013), penambahan PC sampai dengan di bawah 70\% menurunkan ketahanan impak, namun penambahan PC diatas 70\% dapat menaikkan ketahanan impak polipaduan PC/ABS. Serat kaca (SK) yang digunakan jumlahnya divariasi dari 0 ; $5 ; 10$; dan 15 per seratus bagian resin (phr). Bahan aditif lain yang ditambahkan jumlahnya dibuat tetap seperti ABS-g-MA sebanyak 2 phr, anti oksidan Irganox 1010 sebanyak 0,05 phr dan Irgafos P168 sebanyak 0,1 phr.

\section{Pengujian}

Uji densitas dilakukan menggunakan alat electron densimeter EW-200SG merek Mirage. Uji melt flow index (MFI) dilakukan dengan metode ASTM D-1238, untuk PC/ABS tanpa serat kaca dilakukan pada beban $5 \mathrm{~kg}$ suhu $240^{\circ} \mathrm{C}$ dan untuk komposit PC/ABS yang berisi serat kaca dilakukan pada beban $3,8 \mathrm{~kg} 300^{\circ} \mathrm{C}$. Uji kuat impak Izod menggunakan spesimen yang sesuai standar ASTM D256 dan diuji menggunakan alat uji Izod Impact Toyoseiki. Uji kuat tarik menggunakan spesimen yang sesuai standar ASTM D-638 tipe I dan dilakukan pada suhu ruang terkondisi. Karakterisasi gugus fungsi menggunakan Spektrofotometer FTIR dilakukan dengan spesimen bentuk film. Pengujian kristalinitas menggunakan alat XRD merek Shimadzu (target $=\mathrm{Cu}$; voltase $=40$ $\mathrm{kV}$; arus $=30 \mathrm{~mA}$ ). Uji morfologi menggunakan SEM merek Shimadzu, sebelum uji spesimen lebih dahulu dilapisi emas.

\section{HASIL DAN PEMBAHASAN Sifat Fisis}

Pengaruh kandungan serat kaca terhadap sifat fisis komposit $\mathrm{PC} / \mathrm{ABS}$ meliputi pengujian densitas, melt flow index (MFI), ketahanan impak, dan kuat tarik berturut-turut disajikan pada Gambar 1 sampai dengan Gambar 5.

Gambar 1 menunjukkan bahwa penambahan bahan pengisi serat kaca hanya sedikit menaikkan densitas polipaduan PC/ABS. Densitas suatu bahan dipengaruhi oleh void dari sebuah bahan komposit dan densitas juga dapat dipengaruhi oleh ikatan antar muka matriks dan serat. Matriks dan serat yang tidak terikat dengan baik menyebabkan densitas rendah dikarenakan adanya ruang kosong 


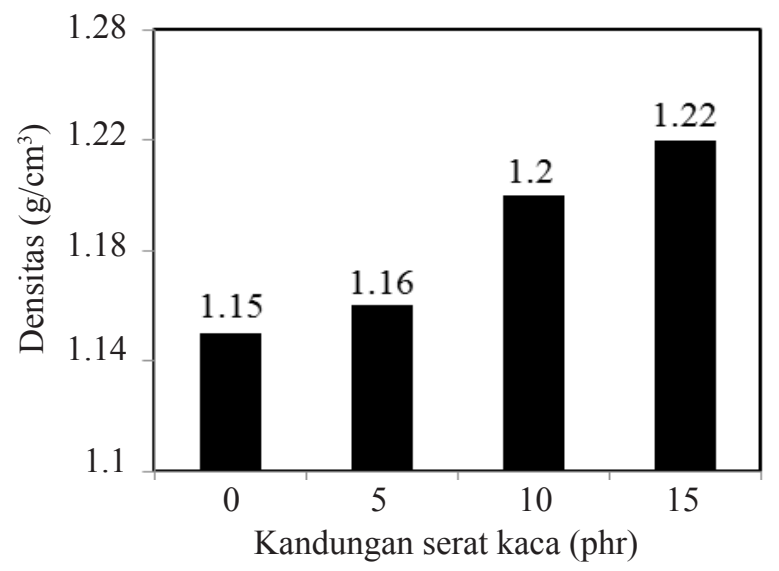

Gambar 1. Pengaruh jumlah serat kaca terhadap densitas komposit PC/ABS.

di sekitar serat yang tidak merekat pada matriks begitu pula sebaliknya. Penambahan serat kaca sebesar 5 phr menaikkan densitas dari polipaduan PC/ ABS sebesar $0,87 \%$, dan penambahan $15 \mathrm{phr}$ hanya menaikkan densitas sebesar $6,09 \%$. Serat kaca

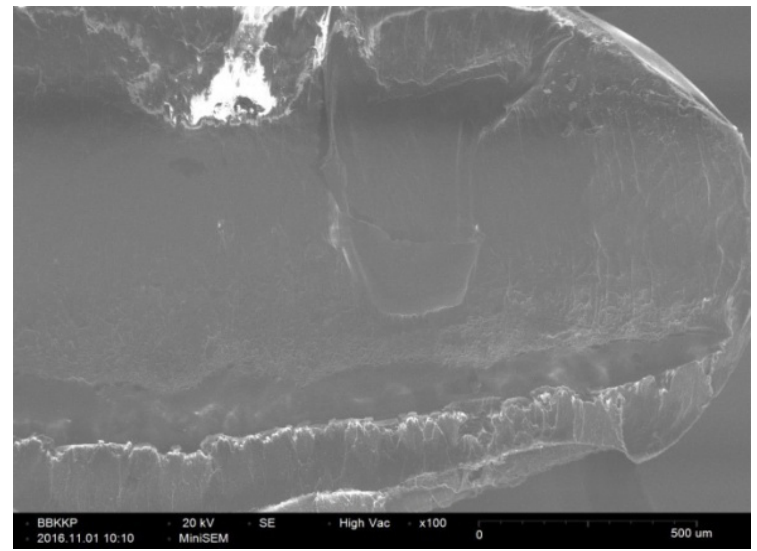

a

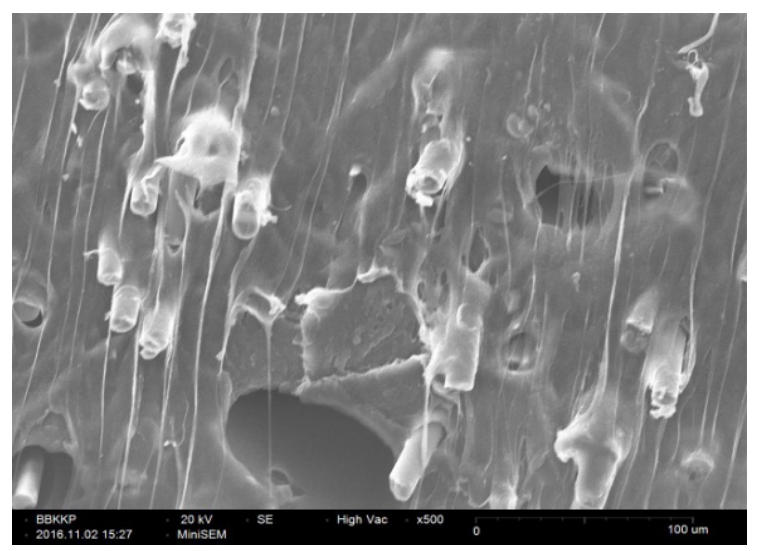

C merupakan bahan pengisi padat dengan densitas yang lebih tinggi dari matriks plastiknya sehingga dengan bertambahnya serat kaca tentu saja akan menaikkan densitas komposit plastik. Hasil SEM pada Gambar 2 memperlihatkan semakin banyak serat kaca maka ruang kosong (void) antara serat dan polimer menurun yang mengakibatkan densitas juga naik.

Gambar 3 menunjukkan bahwa penambahan jumlah serat kaca cenderung menurunkan nilai melt flow index (MFI) dari polipaduan PC/ABS. Polipaduan PC/ABS tanpa serat kaca mempunyai nilai MFI $7 \mathrm{~g} / 10 \mathrm{~min}$, dengan penambahan bahan pengisi serat kaca 5,10 , dan 15 phr nilai MFI berturut-turut turun menjadi 3; 3; dan 2,5 g/10 min. Hal ini seperti hasil penelitian Asyadi et al. (2013) yang melakukan penelitian polipaduan PC/ABS (70/30) dengan diberi bahan pengisi mika juga menurunkan nilai MFI dari $15,8 \mathrm{~g} / 10$ min menjadi $12 ; 8 ; 10,6$; dan $10,2 \mathrm{~g} / 10$ min pada penambahan mika berturut-turut 10,20 , dan 30

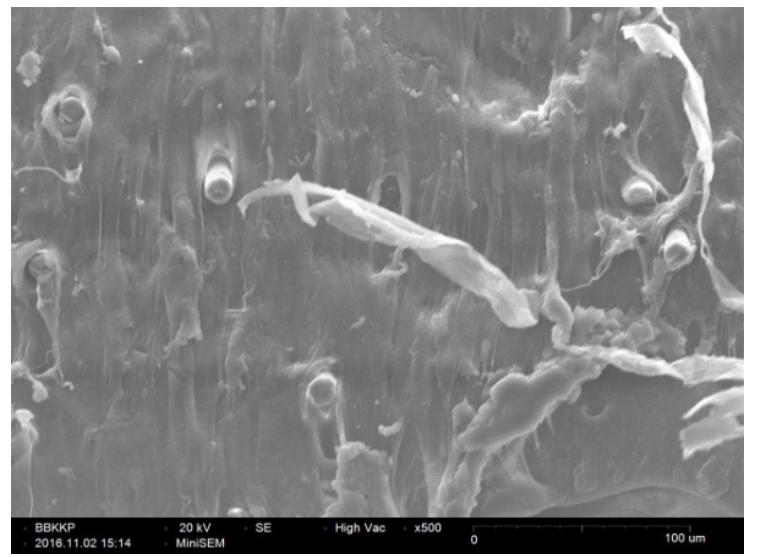

b

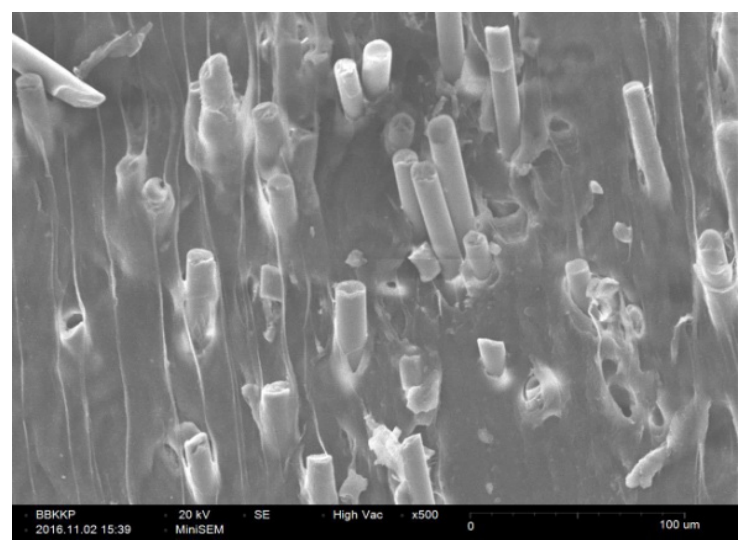

d

Gambar 2. SEM mikrograf: (a) PC/ABS tanpa fiberglass (perbesaran 100x); (b) PC/ABS dengan fiberglass $5 \mathrm{phr}$ (perbesaran 500x); (c) PC/ABS dengan fiberglass $10 \mathrm{phr}$ (perbesaran 500x); (d) SEM mikrograf PC/ABS dengan fiberglass 15phr (perbesaran 500x). 
phr. Hal ini menunjukkan bahwa adhesi dan wettability polimer ke bahan pengisi relatif kecil sehingga dapat menyebabkan laju geser yang lebih tinggi dan aliran lelehan rendah.

Ketahanan impak polipaduan PC/ABS menurun dengan bertambahnya jumlah serat kaca (Gambar 4). Pada penambahan serat kaca 5 phr, $10 \mathrm{phr}$ dan $15 \mathrm{phr}$ terjadi penurunan ketahanan impak berturut-turut sebesar $40,17 \%, 56,78 \%$ dan $68,305 \%$ dibanding tanpa serat kaca. Hal ini menunjukkan bahwa penambahan serat kaca menaikkan kerapuhan dari polipaduan PC/ABS. Hal ini juga sama seperti hasil penelitian Lingesh et al. (2014) yang menunjukkan bahwa penambahan serat kaca $5-30 \%$ dari campuran nilon dan polipropilena (PA66/PP) menunjukkan penurunan ketahanan impak campuran PA66/PP. Namun hasil penelitian Malinosk (2011) menunjukkan bahwa penambahan serat kaca menaikkan ketahanan

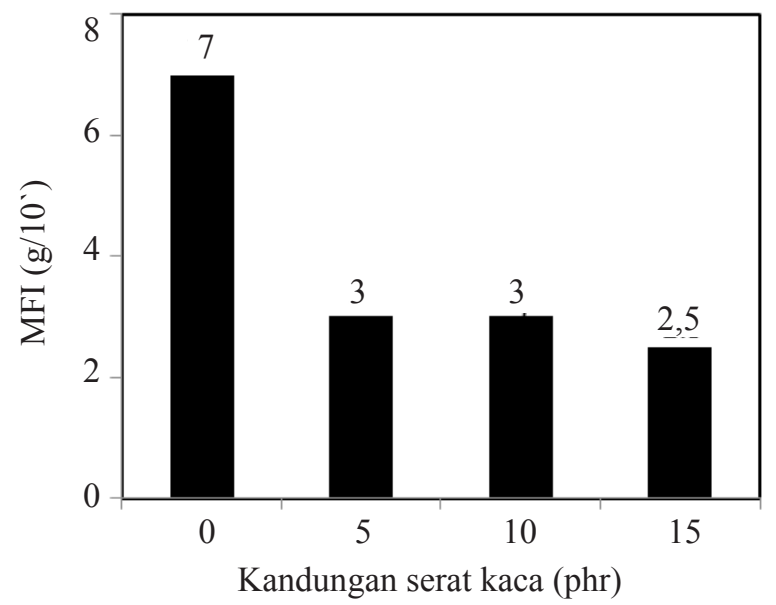

Gambar 3. Pengaruh jumlah serat kaca terhadap melt flow index (MFI) komposit PC/ABS.

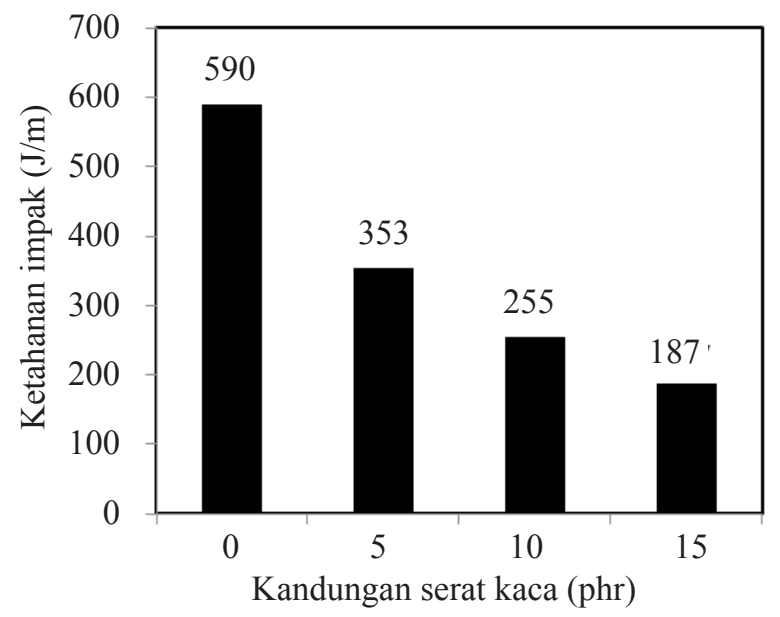

Gambar 4. Pengaruh jumlah serat kaca terhadap ketahanan impak komposit PC/ABS. impak kompon PC dan hasil penelitian Krishna et al. (2013) menunjukkan bahwa penambahan PC yang diperkuat serat kaca $5-30 \%$ menaikkan kekuatan impak PC/ABS.

Kuat tarik suatu material merupakan parameter yang menunjukkan seberapa besar tegangan berupa tarikan yang dapat diterima suatu material sebelum akhirnya putus. Kuat tarik polipaduan PC/ABS tanpa serat gelas sebesar 539 kg.f/ $\mathrm{cm}^{2}$ dengan penambahan serat kaca sebanyak 5 phr menaikkan kekuatan tarik poli paduan $\mathrm{PC} /$ ABS menjadi $640 \mathrm{~kg} . \mathrm{f} / \mathrm{cm}^{2}$ berarti ada kenaikan sebesar $18,73 \%$. Penambahan 15 phr hanya naik $19,67 \%$, berarti dari penambahan $5 \mathrm{phr}$ ke $15 \mathrm{phr}$ hanya naik sedikit yaitu $0,94 \%$ (Gambar 5). Hal ini menunjukkan bahwa serat kaca dapat menempati ruang antarmolekul antara rantai polimer sehingga mengurangi kekuatan sekunder di antara rantai polimer yang menyebakan molekul polimer mudah bergerak dan bila terkena tarikan menyebabkan mudah patah. Hal ini juga seperti hasil penelitian Gaji and Satyanarayana (2016) yang menyatakan kekuatan tarik ABS/serat kaca lebih tinggi dari pada kekuatan tarik ABS murni, Nuruzzaman et al. (2016) juga menyatakan bahwa serat kaca menaikkan kekuatan tarik komposit nilon/serat kaca dimana pada penelitian tersebut membandingkan sifat kuat tarik nilon murni dan komposit nilon yang berisi serat kaca 5\%, 10\%, 15\%, dan 20\%. Hasil penelitian Malinoski (2011) menunjukkan bahwa penambahan serat kaca menaikkan kekuatan tarik kompon PC.

\section{Karakterisasi gugus fungsi}

Karakterisasi gugus fungsi pada resin PC, ABS, polipaduan PC/ABS dan polipaduan $\mathrm{PC} /$

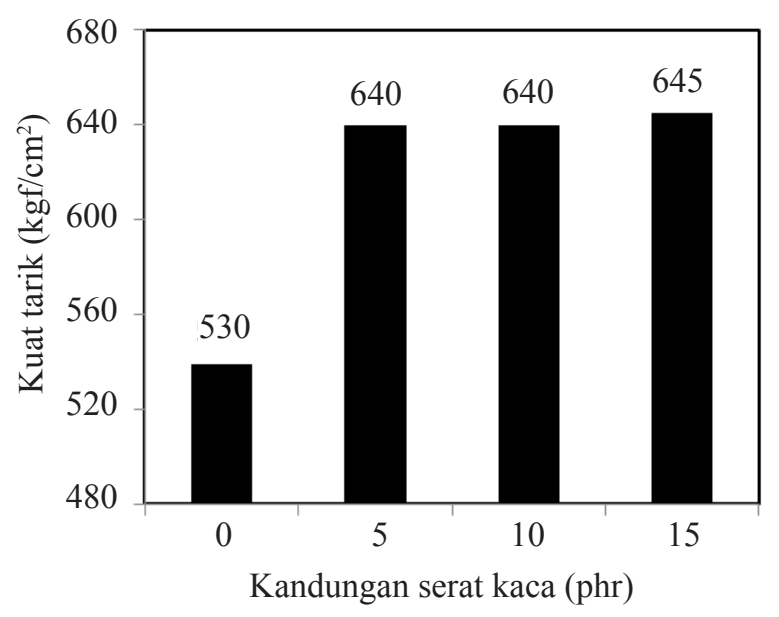

Gambar 5. Pengaruh jumlah serat kaca terhadap kuat tarik komposit PC/ABS. 


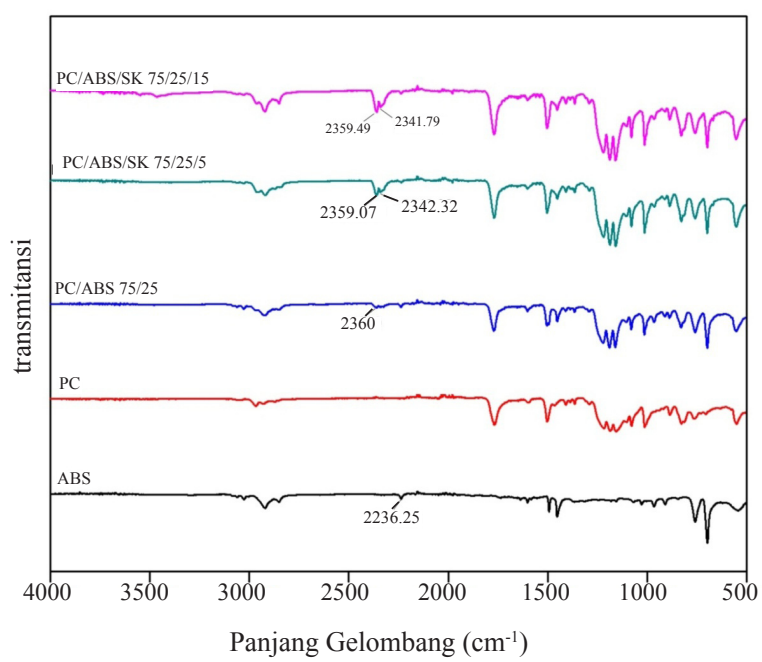

Gambar 6. Spektrum FTIR komposit hasil penelitian.

ABS yang berisi serat kaca dilakukan dengan menggunakan alat fourier transform infra red (FTIR) spectrophotometer dan hasilnya disajikan pada Gambar 6.

Spektra FTIR polikarbonat (Gambar 6) memperlihatkan puncak serapan pada $1384 \mathrm{~cm}^{-1}$ menunjukkan $\mathrm{C}-\mathrm{H}\left(-\mathrm{CH}_{3}\right)$ asimetris dan simetris, serapan pada $1782 \mathrm{~cm}^{-1}(\mathrm{C}=\mathrm{O}$ stretching dari ikatan karbon), dan $1257 \mathrm{~cm}^{-1}$ menunjukkan serapan dari vibrasi isopropylidene dari polikarbonat. Puncak serapan 1597, 1504 dan $1465 \mathrm{~cm}^{-1}$ adalah $\mathrm{C}=\mathrm{C}$ dari cincin aromatik. Spektra FTIR ABS memperlihatkan serapan pada $2237 \mathrm{~cm}^{-1}$ (komponen nitril), $1602 \mathrm{~cm}^{-1}, 1492 \mathrm{~cm}^{-1}, 744 \mathrm{~cm}^{-1}, 690$ $\mathrm{cm}^{-1}$ (cincin aromatik dari stirena), serta serapan komponen butadiene (vinyl) pada $960 \mathrm{~cm}^{-1}$ (trans 1,4) dan $914 \mathrm{~cm}^{-1}$ (trans 1,2). Untuk Spektra yang berisi campuran $\mathrm{ABS} / \mathrm{PC}$ menunjukkan adanya serapan pada $2932 \mathrm{~cm}^{-1}$ yang menunjukkan butadiene $\mathrm{CH}_{2}$ - stretching, dan $2960 \mathrm{~cm}^{-1}$ yang menunjukkan pita serapan $\mathrm{CH}_{3}$ - stretching dari polikarbonat. Menurut Krache and Debbah (2011) pada spektrum IR PC/ABS, bila tidak memperlihatkan adanya spesies teroksidasi sekitar $3200-3300 \mathrm{~cm}^{-1}$ di homopolimer, ini berarti bahwa polimer tidak mengalami degradasi yang signifikan selama pemrosesan. Hal ini juga diperlihatkan pada Gambar 6 tidak adanya puncak serapan di daerah 3200-3300 $\mathrm{cm}^{-1}$, ini berarti spektra FTIR polipaduan PC/ABS tidak menunjukkan plastik yang terdegradasi. Secara umum, spektrum tidak menunjukkan perbedaan yang signifikan antar spektrum PC murni dan ABS murni, itu berarti bahwa tidak ada reaksi kimia antara PC dan ABS. Spektra yang berisi se-

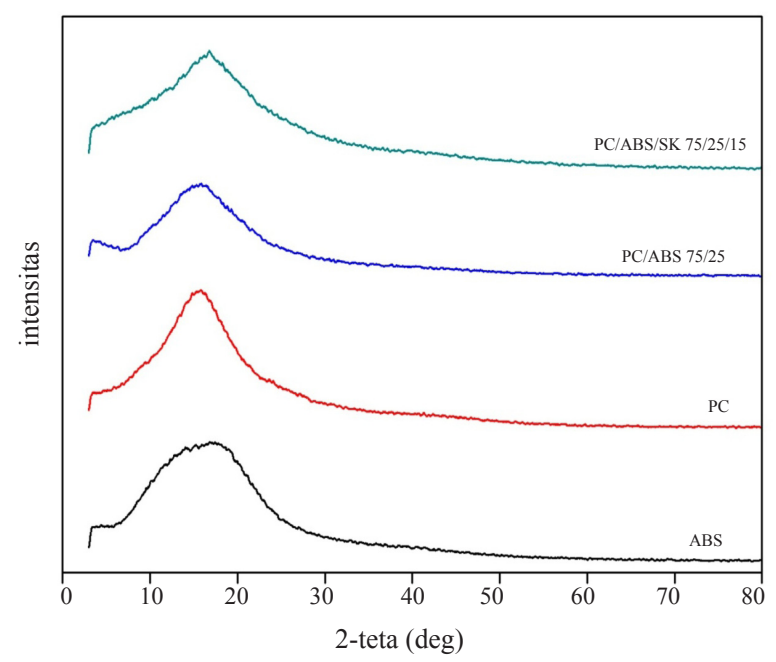

Gambar 7. XRD polipaduan PC/ABS plastik hasil penelitian.

rat kaca menunjukkan adanya serapan $\mathrm{Si}-\mathrm{O}-\mathrm{Si}$ di daerah 900-1100 $\mathrm{cm}^{-1}$. Serapan sekitar $1100 \mathrm{~cm}^{-1}$ juga bisa diartikan adanya ikatan $\mathrm{C}-\mathrm{O}$ dan $\mathrm{Si}-\mathrm{O}$ yang bisa menunjukkan adanya ikatan plastik dengan $\mathrm{SiO}_{2}$. Secara umum tidak ada gugus fungsi yang baru yang terdeteksi dengan masuknya serat kaca ke dalam polipaduan $\mathrm{PC} / \mathrm{ABS}$ berarti tidak ada ikatan kimia antara PC/ABS dan serat kaca.

\section{Hasil uji X-ray Diffraction (XRD)}

Karakterisasi XRD bertujuan untuk menganalisis struktur kristal pada komposit $\mathrm{PC} / \mathrm{ABS} /$ serat kaca. Hasil uji XRD untuk plastik PC, ABS, polipaduan $\mathrm{PC} / \mathrm{ABS}$ tanpa serat kaca maupun yang berisi serat kaca disajikan pada Gambar 7 .

Gambar 7 memperlihatkan tiga puncak terkuat untuk PC pada 2-theta $15,78^{\circ}, 15,26^{\circ}$ dan $16,28^{\circ}$, untuk $\mathrm{ABS}$ pada 2 -theta $18,12^{\circ}, 18,94^{\circ}$, dan $17,42^{\circ}$, untuk PC/ABS $75 / 25$ tanpa serat kaca pada 2 -theta $15,88^{\circ}, 15,28^{\circ}$, dan $16,40^{\circ}$, serta untuk PC/ABS 75/25 yang berisi serat kaca $15 \mathrm{phr}$ pada 2-theta $16,74^{\circ}, 16,16^{\circ}$ dan $17,16^{\circ}$. Gambar 7 memperlihatkan bahwa ABS memiliki nilai 2-theta yang lebih besar dari PC berarti ABS lebih amorf dibanding PC. Perbandingan PC/ABS 75/25 membuat nilai 2-theta menyerupai PC. Adanya serat kaca membuat komposit PC/ABS lebih amorf. Nilai 2-theta untuk komposit PC/ABS yang berisi serat kaca 15 phr lebih tinggi dari nilai 2-theta PC/ ABS tanpa serat kaca.

\section{KESIMPULAN}

Pengaruh serat kaca terhadap sifat mekanik komposit $\mathrm{PC} / \mathrm{ABS}$ menunjukkan bahwa serat kaca 
yang ditambahkan sampai $15 \mathrm{phr}$ menaikkan densitas, dan kekuatan tarik namun menurunkan MFI dan kekuatan impak. Spektrum FTIR menunjukkan bahwa tidak ada reaksi kimia antara PC, ABS dan serat kaca serta polimer yang diproses tidak mengalami degradasi. Adanya serat kaca membuat komposit PC/ABS lebih amorf. Nilai 2-theta untuk komposit $\mathrm{PC} / \mathrm{ABS}$ yang berisi serat kaca 15 phr lebih tinggi dari nilai 2-theta $\mathrm{PC} / \mathrm{ABS}$ tanpa serat kaca.

\section{UCAPAN TERIMA KASIH}

Penulis mengucapkan terimakasih kepada Kepala Balai Besar Kulit, Karet dan yang telah memberi kepercayaan untuk melakukan penelitian dan kepada Tim Kelompok Kerja 1866.001.001.021 tahun 2016 yang telah membantu penelitian ini sampai selesai.

\section{DAFTAR PUSTAKA}

Asyadi, F., Jawaid, M., Hassan, A., \& Wahit, M.U. (2013). Mechanical properties of mica-filled polycarbonate/poly(acrylonitrile-butadiene-styrene) composites. Polymer-Plastics Technology and Engineering, 52, 727-736, https://doi.org/10.1080/03602559.2012.762672

Avdeeva, A., Shlykova, I., Perez, M., Antonova, M., $\&$ Belyaeva, S. (2016). Chemical properties of reinforcing fiberglass in aggressive media, MATECWeb of Conferences, 53, 1-9, https://doi.org/10.1051/matecconf/20165301004

Gaji, B.S., \& Satyanarayana, G.M. (2016). Characterization of mechanical properties of ABS/glass fiber polymer matrix composites, National Conference on Emerging Trends in Mechanical Engineering, April 2016, 1-5.

Hemanth, R., Sekar, M., \& Suresha, B. (2014). Effects of fibers and fillers on mechanical properties of thermoplastic composites. Indian Journal of Advances in Chemical Science, 2, 28-35.
Ho, M. H., Wang, P. N., Yeh, J. P., \& Li, S. J. (2015). Research on fatigue fracture characterization of PC/ABS blend, 5th International Conference on Advanced Design and Manufacturing Engineering (2015), 1899- 1902, https://doi.org/10.2991/icadme-15.2015.351

Krache, R., \& Debbah, I. (2011). Some mechanical and thermal properties of PC/ABS blends. Materials Sciences and Applications, 2(5), 404-410, https://doi.org/10.4236/msa.2011.25052

Krishna, T.P., Srinivasababu, N., Babu, N.R., \& Adhikari, S. (2013). Assessing the impact performance of PC/ABS blends on addition of PC with glass. Indian Journal of Applied Research, 3(2), 121-122,

Lingesh, B.V., Rudresh, B.M., \& Ravikumar, B. N. (2014). Effect of short glass fibers on mechanical properties of polyamide66 and polypropylene (PA66/PP) thermoplastic blend composites. Pocedia Materials Science, 5, 1231-1240, https://doi.org/10.1016/j.mspro.2014.07.434

Samakrut, N., Krailas, S., \& Rimdusit, S. (2008). Characterization of short glass fiber-reinforced PC/ ABS blends. Journal of Metals, Materials and Minerals, 18(2), 207-211.

Malinoski, J. (2011). Fiber glass-reinforced polycarbonate compounds. http://www.ceramicindustry. com/articles/92204-fiber-glass-reinforced-poly carbonate-compounds, diakses 15 Maret 2016.

Nuruzzaman, D. M., Iqbal, A. K. M., Oumer, A. N., Ismail, N. M., \& Basri, S. (2016). Experimental investigation on the mechanical properties of glass fiber reinforced nylon. IOP Conf. Series: Materials Science and Engineering, 114(2016), 1-7, https://doi.org/10.1088/1757-899X/114/1/012118 